
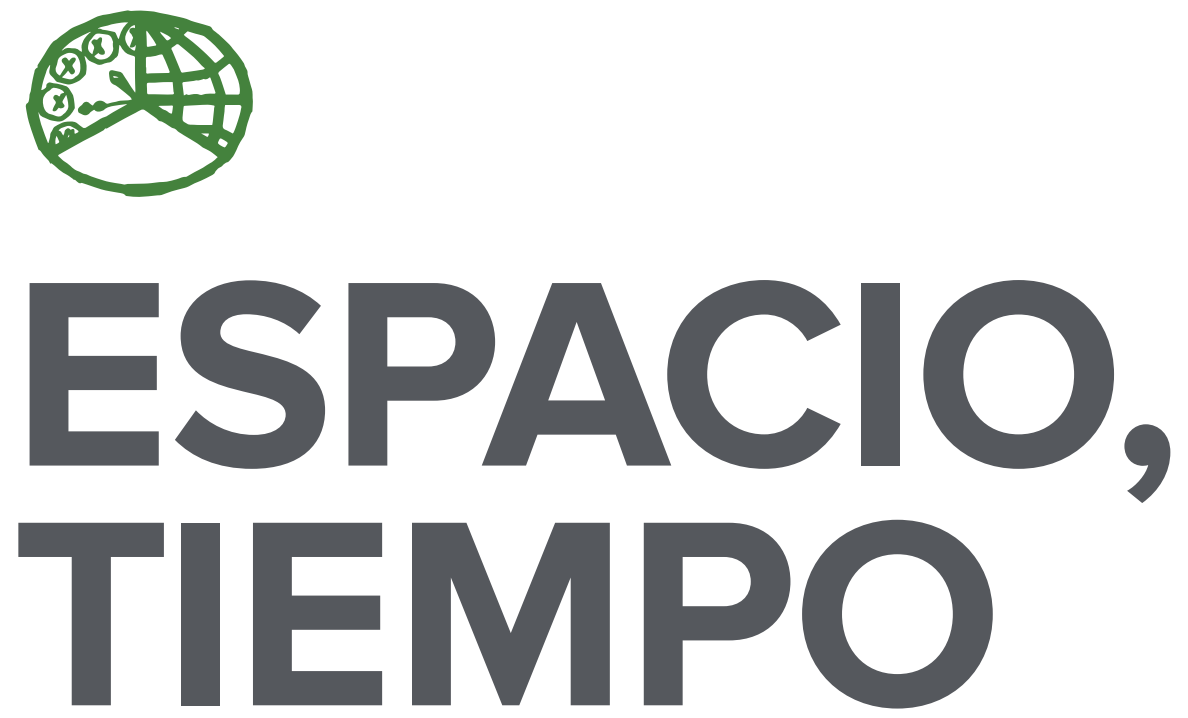

AÑO 2021

ISSN 1130-2968

E-ISSN 2340-146X
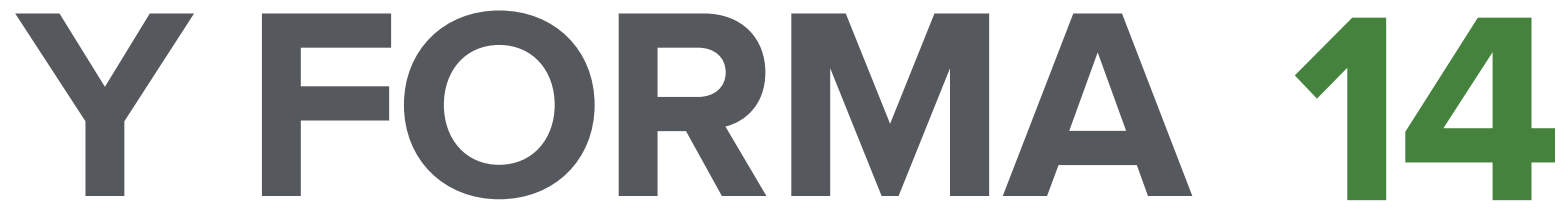

SERIE VI GEOGRAFİA

REVISTA DE LA FACULTAD DE GEOGRAFÍA E HISTORIA 


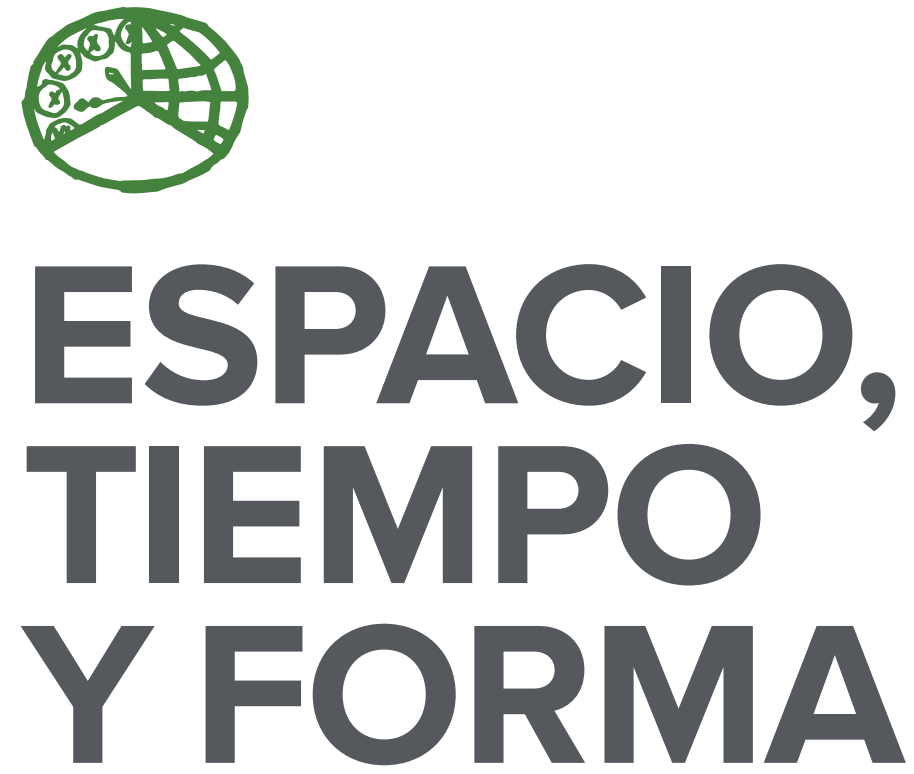

AÑO 2021

ISSN 1130-2968

E-ISSN 2340-146X

SERIE VI GEOGRAFÍA

REVISTA DE LA FACULTAD DE GEOGRAFİA E HISTORIA

DOI: https://doi.org/10.5944/etfvi.14.2021

\section{UחED}

UNIVERSIDAD NACIONAL DE EDUCACIÓN A DISTANCIA 
La revista Espacio, Tiempo y Forma (siglas recomendadas: ETF), de la Facultad de Geografía e Historia de la UNED, que inició su publicación el año 1988, está organizada de la siguiente forma:

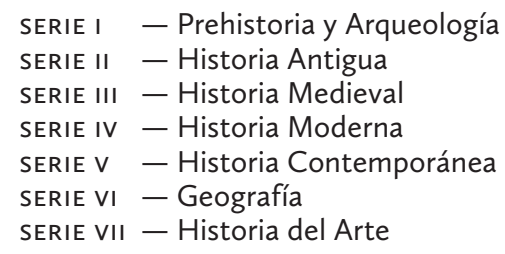

Excepcionalmente, algunos volúmenes del año 1988 atienden a la siguiente numeración:

$$
\begin{aligned}
& \mathrm{N}^{\circ} 1 \text { - Historia Contemporánea } \\
& \mathrm{N}^{\circ} 2 \text { - Historia del Arte } \\
& \mathrm{N}^{\circ} 3 \text { - Geografía } \\
& \mathrm{N} .^{\circ} 4 \text { - Historia Moderna }
\end{aligned}
$$

ETF no se solidariza necesariamente con las opiniones expresadas por los autores.

\author{
UNIVERSIDAD NACIONAL DE EDUCACIÓN A DISTANCIA \\ Madrid, 2020 \\ SERIE VI - GEOGRAFÍA N. ${ }^{\circ} 14,2021$ \\ ISSN 1130-2968 - E-ISSN 2340-146x \\ DEPÓSITO LEGAL \\ $M-21.037-1988$ \\ URL \\ ETF VI · GEOGRAFÍA · http://revistas.uned.es/index.php/ETFVI \\ DISEÑO Y COMPOSICIÓN \\ Carmen Chincoa Gallardo · http://www.laurisilva.net/cch \\ Impreso en España · Printed in Spain
}




\section{ARTÍCULOS · ARTICLES}





\title{
INFANCIA, POBREZA Y DEPORTE EN EL DESIERTO DE CALAMA, CHILE. REPRESENTACIONES SOCIALES EN "SEGUNDO TIEMPO, ÚLTIMO GOL GANA»
}

\author{
CHILDHOOD, POVERTY AND SPORT IN THE DESERT \\ OF CALAMA, CHILE. SOCIAL REPRESENTATIONS \\ IN «SEGUNDO TIEMPO, ÚLTIMO GOL GANA»
}

\author{
David García-Reyes¹, Enrico Marini² y Marta Gallardo³ \\ Recibido: 29/01/2021 - Aceptado: 11/03/2021 \\ DOI: https://doi.org/10.5944/etfvi.14.2021.29511
}

\begin{abstract}
Resumen
Las representaciones del cine de ficción nutren el imaginario colectivo, caracterizando elementos que proyectan la percepción social. El trabajo se centra en el cine de Andrés Wood, concretamente en el segmento «Segundo tiempo. Calama. Último gol gana» de su primer largometraje, para observar y analizar la representación de la pobreza y la exclusión en la infancia, en un ámbito geográfico extremo como el desierto de Calama (Chile) y en un contexto económico de reconversión como el sector minero, donde el deporte se convierte en un vehículo para el aprendizaje, la socialización y la toma de responsabilidades.
\end{abstract}

Palabras clave

Cine; representaciones sociales; desierto; deporte; pobreza; infancia; Calama; Chile.

\section{Abstract}

Fiction films representations nourishes the collective imaginary. The research analyzes Andres Wood's filmography and in particular the chapter «Segundo Tiempo. Calama. Último gol gana» of his first film, to observe and understand the representation of poverty and exclusion in childhood, related to an extreme geographical area, such as the dessert of Calama (Chile,) and a mining sector

\footnotetext{
1. Facultad de Humanidades y Arte, Universidad de Concepción (Chile); davgarciareyes@gmail.com; ORCID: https://orcid.org/0000-0003-3445-1304

2. Alma Mater Studiorum-Università di Bologna (Italia); menr81@gmail.com; ORCID: https://orcid. org/0000-0002-5580-0633

3. Departamento de Geografía, Universidad Nacional de Educación a Distancia (España); martagallardo@geo. uned.es; ORCID: http://orcid.org/0000-0003-4804-710X
} 
reconversion as the economic background where sport becomes a mean for learning and socialization.

\section{Keywords}

Cinema; social representations; desert; sport; poverty; childhood; Calama; Chile. 


\section{INTRODUCCIÓN}

Los productos culturales, como la literatura o el cine, presentan una combinación multimodal de significados que ofrecen una reconfiguración cultural de experiencias y que transforman a nivel mundial la percepción social e institucional de las personas (Gillespie y Zittoun, 2013). Las representaciones fílmicas son representaciones flotantes y líquidas, más o menos conscientes, que condicionan nuestra aprehensión de la realidad (Imbert, 20Io). Los relatos audiovisuales se ocupan de representar a distintas colectividades pudiendo impactar en la audiencia con diferentes formas de recepción, estableciendo o creando modelos estereotipados a seguir (Buccafusca, 2015), pero también combatiéndolos.

La exploración de las representaciones fílmicas desde la mirada del investigador social constituye un enorme potencial analítico. Por este motivo, el cine se erige en un instrumento de gran valor en sus atributos para estudiar las representaciones socioeconómicas, del mismo modo y utilidad que otras técnicas de encuesta de la realidad social, dilucidando algunas de las reflexiones que, prospectivamente, pueden ser extraídas del análisis de realidades y construcciones sociales a través del cine. El medio puede aspirar a convertirse en un retrato lo más fiel posible sobre cuestiones sociales y culturales favoreciendo la consideración del cine como herramienta para el estudio sociocultural, como una aplicación y una técnica para el aprendizaje de cuestiones fundamentales que atañen a la configuración de los imaginarios sociales. Así, a lo largo de las últimas décadas, la relación producida entre el cine y diversos aspectos de las representaciones sociales a través de sus formas narrativas se ha configurado como un recurrente objeto de estudio, abordando diferentes temáticas, como pueden ser cuestiones de raza y género (Buccafusca, 2015; Erigha, 2015), LGTBI (Stevens, 2013; Shaw, 2014; Madzarevic y Soto-Sanfiel, 20I8), religiosas (Plate, 2003), relacionadas con la pobreza (Goldgel-Carballo, 20I4; Streib et al., 20I6; Jarman, 20I7), la infancia (May y Ramsland, 2007; Hockenhull, 20I8), problemáticas migratorias (Schurmans, 20I5; Colella, 20I7), el envejecimiento (Ogando-Díaz, 20I6; Atkinson y Plew, 20I7) o la discapacidad (Gauci y Callus, 2015).

En cuanto a la representación de la infancia y la pobreza en el cine, son numerosas las películas contemporáneas que muestran ambas temáticas (Sinyard, I992), destacando cintas pioneras en esta temática rodadas entre los años veinte y cuarenta del siglo pasado, como el filme silente The Kid (Charles Chaplin, I92I) o la francesa Zéro de conduite: Jeunes diables au collège (Jean Vigo, 1933). Dentro del contexto latinoamericano, algunos films imprescindibles desde mediados del siglo pasado son Los olvidados (Luis Buñuel, I950), Crónica de un niño solo (Leonardo Favio, 1965), Valparaíso mi amor (Aldo Francia, I969), Pixote a lei do mais fraco (Héctor Babenco, I980), La vendedora de rosas (Víctor Gaviria, I998), La virgen de los sicarios (Barbet Schroeder, 2000), Alicia en el país (Esteban Larraín, 2008) o la más reciente Capitães da Areia (Cecilia Amado, 20II). En cuanto a situaciones de marginalidad, pobreza y deporte, y más concretamente el fútbol, tema tratado en este trabajo, se han producido significativos films, desde Pelota de trapo (Leopoldo Torres Ríos, I948), sobre el ascenso social de un niño de familia obrera como jugador de fútbol 
en la Argentina de finales de los cuarenta, o Mossafer (Abbas Kiarostami, 1974) que trata la obsesión de un adolescente por el fútbol en el Irán más profundo y rural.

Todas estas referencias aparecen vinculadas a una tradición secular de temas relacionados con la infancia, la pobreza y la marginalidad, pero, además, concretamente, la afición al fútbol aparece en uno de los títulos más emblemáticos de la cinematografía argentina de los setenta. Si se piensa en la representación de estos elementos, sobresale La Raulito (I975) de Lautauro Murúa, largometraje que toma la vida y el apelativo de María Esther Duffau, la hincha más conocida del club Boca Juniors y que curiosamente tuvo un pequeño papel en Pelota de trapo. La cinta con rasgos neorrealistas se ocupa de mostrar algunos de los pequeños delitos de la Raulito y de cómo sobrevive en un mundo en el que su apariencia masculinizada, los rigores de su existencia callejera y su desarraigo familiar la llevarán a centros de reclusión y psiquiátricos. El éxito de la cinta supuso que se rodase una secuela que atendía de nuevo, desde la ficción, al devenir vital y mediático del personaje; Marilina Ross volvió a encarnar a la protagonista de La Raulito en libertad (I977) de nuevo dirigida por Murúa, cineasta chileno radicado en Argentina desde finales de los años cincuenta, y que obtuvo un éxito considerable con estas dos películas. Los espacios periféricos bonaerenses de la Boca volverían a proyectarse tres décadas después al hacer un recorrido por la vida y el impacto mediático y social de Duffau en el documental La Raulito, golpes bajos (2009) de Emiliano Serra.

Entre otras producciones centradas en integrar temáticamente el fútbol, urgencias sociales y periferias urbanas, sobresale el director Ken Loach, que ha tratado el tema de la exclusión social y el fútbol en My name is Joe (I998) y Looking for Eric (2009), retratando la precariedad de la clase trabajadora junto a la práctica y la afición por el llamado deporte rey. El cine brasileño ha sido especialmente prolífico en temáticas atravesadas por la infancia y el fútbol en contextos marginales, como ponen de manifiesto títulos como Cidade de Deus (Kátia Lund y Fernando Meirelles, 2002), fresco social en el que el fútbol es un divertimento evasivo frente a la cruda realidad de una vida criminal a la que se ven abocados los niños; $O$ ano em que meus pais saíram de férias (Cao Hamburger, 2006), ambientada en el verano de i970 y la Copa Mundial de fútbol celebrada en México, en la que un niño brasileño mitiga la ausencia de sus padres -opositores políticos- durante la dictadura brasileña gracias a dicha competición; o el drama social contemporáneo en Aspirantes (lves Rosenfeld, 2015). El enfrentamiento social que supone la prosperidad en el fútbol de jóvenes criados en un contexto lumpenesco también tiene presencia en la cinta venezolana Hermano (Marcel Rasquin, 2010); o en las aspiraciones de superar una infancia marcada por territorios en guerra y con un balón de fútbol como hilo conductor en la coproducción colombo-panameña Los colores de la montaña (Carlos César Arbeláez, 20Io), así como algunos ejemplos del cine español más reciente, que se ha ocupado de ofrecer miradas periféricas en torno al fútbol y a situaciones de enorme exclusión como la homofobia o el tráfico de seres humanos vinculados lateral o frontalmente con el deporte como demuestran respectivamente la hispanocubana La partida (Antonio Hens, 2013) o Diamantes negros (Miguel Alcantud, 2013).

El cine chileno más reciente también se ha dedicado a estas temáticas, desde la cinta hagiográfica Mi amigo Alexis (Alejandro Fernández Almendras, 20I9), narración 
que relata la amistad de la estrella deportiva Alexis Sánchez con un niño en el que ve reflejada su infancia, o la dura historia de Parío y criao (Jorge Donoso, 2019), sobre la azarosa existencia de Yorman, un adolescente colombiano que vive en la ciudad nortina de Antofagasta y que en su condición de migrante y de excluido social, trata de labrarse un futuro en el fútbol mientras soporta ataques racistas y la presión de su abuela con la que vive y que a diferencia de Yorman aspira a volver a su país de origen.

Dos décadas antes, Historias de futbol (Andrés Wood, 1997) retrataba la relación de los habitantes de diferentes ciudades chilenas, desde la nortina y desértica ciudad minera de Calama al archipiélago sureño de Chiloé, con el futbol. Este trabajo se centra en analizar el segundo de los tres segmentos que componen la película, donde se interrelacionan infancia, pobreza y futbol en un contexto geográfico aislado: el desierto de Atacama. «Segundo Tiempo. Calama. Último gol gana» presenta características sobresalientes para ser analizado e interpretado desde las representaciones socioeconómicas del extremo norte del país. Se rueda en un poblamiento vinculado a las actividades relacionadas con la minería del cobre, en un contexto urbano, social, y económico dependiente de esta actividad. El contexto urbano extremo y de exclusión de la infancia que se muestra está mediado por el deporte. Se trata de un realismo basado, no tanto en el costumbrismo que se le ha atribuido a Wood (Peirano, 2005), sino a las circunstancias sociales y vitales que sufren los personajes del relato y a una construcción narrativa muy vinculada a cuestiones que se han perpetuado dentro de los imaginarios identitarios de Chile. El film muestra el valor social del fútbol, representándose las dos vertientes de juego y de deporte-espectáculo, metáforas de la propia sociedad chilena.

\subsection{EL NORTE CHILENO EN EL CINE NACIONAL}

Durante el período de la transición democrática (I990-I999), el cine chileno sobresale por su capacidad para representar y fijar en el imaginario colectivo rasgos prexistentes de su identidad nacional. La cohesión social está muy presente en la configuración identitaria del Norte chileno, debido, en parte, a un proceso fijado y proyectado en el imaginario a partir de la literatura de Andrés Sabella o Mario Bahamonde, que atienden con profusión a las realidades nortinas y que, en un proceso de chilenización, disponen y ordenan tradiciones y espacios completamente distintos a los que podían conformar el país antes de la incorporación de los territorios ganados por Chile durante la Guerra del Pacifico (I879-I884).

A pesar de ello, el Norte chileno ha sido mostrado esporádicamente en el audiovisual nacional a lo largo de su historia. Una situación motivada porque el centro de producción y de difusión del cine nacional es sinónimo también de una dependencia centralista en la Región Metropolitana. Pueden destacarse historias ambientadas en las realidades nortinas, como Caliche Sangriento (Helvio Soto, 1969) durante la Guerra del Pacifico; La Araucana (Julio Coll, I97I), improbable reconstrucción de las incursiones coloniales de Pedro de Valdivia; El Entusiasmo (Ricardo Larraín, I998), drama contemporáneo ambientado en Arica y Antofagasta; Nostalgia de la 
luz (Patricio Guzmán, 20Io), evocador documental sobre astronomía y memoria; Sal (Diego Rougier, 20II), atípico western moderno ambientado en el desierto de Atacama; La danza de la realidad (Alejandro Jodorowski, 20I3), film biográfico sobre la infancia del artista en su Tocopilla natal; la coproducción Mirage d'amour avec fanfare (Hubert Toint, 20I6), adaptando una de las novelas de la Pampa salitrera escrita por el novelista Hernán Rivera Letelier; Tierra Yerma (Miriam Heard, 20I6) sobre el regreso de dos mercenarios chilenos, después de su experiencia en la guerra de Irak, al Altiplano nortino de donde son oriundos; o las más recientes Medea (Alejandro Moreno, 20I9), adaptación del drama griego de Eurípides en los espacios del desierto atacameño, y la antes nombrada Parío y criao (Jorge Donoso, 2019).

En esta tendencia, destaca la obra del director santiaguino Andrés Wood (1965) con obras originales, significativas y descentralizadoras como la analizada en este trabajo, Historias de Fútbol (1997), en la que no es complicado advertir el carácter del pampino y la idiosincrasia nortina. El cine de Wood tiene una representación urbana y una implicación social, y de ahí el interés por analizar su trabajo (García-Reyes y Gallardo, 2015). En Wood encontramos las caracterizaciones autorales que permiten que los creadores cinematográficos sean testigos «de cambios fundamentales en el urbanismo contemporáneo» (Nieto Codina, 20II, p. I24). Así, se pueden mencionar aportaciones previas que han señalado elementos vinculados al estudio identitario nacional (Peirano, 2005), la representación socioeconómica latitudinal chilena (Gallardo y García-Reyes, 20I8) y los procesos filmoliterarios del largometraje de Wood (García-Reyes, 2018).

\section{METODOLOGÍA}

De forma sistemática, los distintos parámetros a estudiar mediante el análisis del segmento «Segundo Tiempo. Calama. Último gol gana» se conforman, sucintamente, en los siguientes ítems:

* La ciudad de Calama y el desierto. Representaciones geográficas y socioeconómicas.

* El futbol como elemento de cohesión social, catalizador de valores y herramienta capitalista.

* Representaciones de la pobreza y la infancia en el desierto, marcadas por las condiciones climáticas, atenuantes de la exclusión.

El objetivo es analizar la interrelación de los tres elementos: infancia, pobreza y deporte, en un contexto geográfico extremo, y cómo estos son representados a través del film. Para ello se han analizado diferentes fuentes bibliográficas (libros, capítulos de libro y artículos especializados) en torno a los tres ítems mencionados y las interrelaciones que estos presentan (cine e infancia; cine y pobreza; infancia y pobreza; y cine, infancia y pobreza, encontrando para este último un menor número de casos de estudio). Esto permite observar diferentes conexiones entre 
nuestro ámbito de estudio, la crítica precedente y las reflexiones previas planteadas por otros autores.

Asimismo, se ha realizado un análisis pormenorizado y exhaustivo del material filmado, con el objeto de identificar, nuevamente los tres ítems mencionados a lo largo de la película, y sus interrelaciones, observando también si existe una evolución en el tratamiento de las características mencionadas.

Por otra parte, se han geolocalizado algunos de los lugares que aparecen en film, haciendo uso de las imágenes áreas que proporciona Google Earth y la aplicación de Street View de Google Maps.

Debido a la situación de la pandemia derivada del Covid-ı9 y a la imposibilidad de realizar viajes y trasladarse a otras provincias, no se ha podido realizar un trabajo de campo para poder obtener una cartografía de más detalle en relación con sus localizaciones y observar los posibles cambios que se han dado en su paisaje urbano desde el rodaje del film.

Por último, mencionar que el enfoque de este artículo tiene un planteamiento similar al elaborado por Felipe Vergara (20I4), abordonando la verificación de las problemáticas urbanas y sociales de la ciudad de Calama a partir de la narración cinematográfica y extrayendo valiosas lecciones vinculadas al espacio geográfico.

\section{RESULTADOS}

«Segundo Tiempo. Calama. Último gol gana» es el segundo capítulo del largometraje y la libre adaptación por parte de Wood y de Réne Arcos, coguionista, del cuento «Cuando me gustaba el fútbol» (Micaela y otros cuentos, 1976), del escritor ecuatoriano Raúl Pérez Torres (I94I). El cuento se publicó en la etapa posterior al llamado «boom» de la literatura latinoamericana, siendo una de las obras más importantes del autor e inscrita en lo que se conoce como la «nueva narrativa ecuatoriana» (Ortega Caicedo, 20I0, pp. I9-20). La centralidad del fútbol, verdadero hilo conductor del cuento de Pérez Torres y del largometraje dirigido por Wood, hace que no se pueda pasar por alto el papel social y simbólico de dicho deporte.

El horizonte narratológico de Wood se sirve del texto literario para transferir algunas de las constantes al relato audiovisual, interiorizando en la subjetividad de los personajes y en la que «más que la descripción de la realidad externa importa la percepción que de ella tienen los personajes, lo que ocurre en la conciencia de ellos» (Ortega Caicedo, 20Io, p. 20). La película se encuentra signada por los diálogos naturalistas del relato, junto a la incorporación de actores en las que serán sus primeras y, en la mayoría de los casos, únicas experiencias interpretativas. Los niños de la película son un grupo de «actores» que se interpretan a sí mismos en la ficción y que muestran su cotidianeidad. En «Último gol gana» los guionistas adaptan libremente el cuento, alterando la ubicación de la trama y el desenlace, extrapolándose los suburbios quiteños al paisaje calameño. La acción se traslada de una latitud a otra y amplía la trama desde el punto de vista anecdótico y contextual, modificando también el devenir dramático y aportando una visión muy próxima a la realidad social filmada. Tanto el cuento como el film de Wood denuncian la 
situación de la pobreza en la infancia en un contexto de miseria social, ajena y sistemáticamente ignorada por las voluntades y las responsabilidades políticas.

Wood cuenta la historia secuencialmente a través de Pablo, un niño calameño de unos doce años que vive en una modestísima casa integrada en el interior de un barrio de barracones a finales de los años noventa del siglo XX. La familia del protagonista sufre estrecheces económicas y el joven tiene el fútbol como principal vía de escape. Los rituales del juego, la calle y el espacio desértico ambientan distintas situaciones en las que el protagonista se verá obligado a aceptar el tránsito de la niñez a la edad adulta. Un tránsito que en la película está simbolizado por la pelota de fútbol del equipo del Cobreloa, que pasa de ser un simple juego para convertirse en un valor monetario para una transacción.

\subsection{CALAMA Y EL DESIERTO}

El norte de Chile ilustra el origen nacional de la riqueza de materias primas, desde las explotaciones salitreras a finales del siglo XIX y primeras décadas del siglo XX, junto con las minas de cobre desde mediados del siglo pasado hasta la actualidad. Las diferentes fiebres mineras conllevaron un importante trasvase demográfico desde otras regiones del país, desde el sur partieron muchos trabajadores a buscar oportunidades en el desierto pampino, junto a otros migrantes llegados desde distintos lugares del mundo, conformándose el Norte chileno en un mosaico multicultural y étnico. La ciudad de Calama tiene su razón de ser en torno a las actividades económicas relacionadas con la industria y la extracción mineral del cobre, presentando la Región el producto interior bruto más alto del país.

En la Calama filmada a mediados de los noventa se aprecia la efímera y modesta arquitectura de la ciudad nortina junto a espacios que subrayan la precariedad urbana y económica de sus pobladores. Wood no muestra en ningún momento la tierra de promisión que es o fue la ciudad para muchos de los chilenos que migraron hasta allí con objeto de mejorar sus condiciones de vida. La fatalidad de situarse sobre y alrededor del origen de su riqueza y prosperidad, convierten a Calama en una contradicción urbana por la escasez de vivienda y la privación de otros servicios básicos en el momento en el que se rodó la película, unas condiciones que más de dos décadas después no han variado demasiado.

En el segmento cinematográfico se hace evidente la visualización de un contraste, la imposición urbana y antrópica en claro conflicto con un lugar extremo (Figura i) en el que las circunstancias para la subsistencia no sólo son de índole económica, sino que están marcadas por la propia realidad de su orografía y un escenario extremo que, en un principio, no favorece la creación de entornos sociales por el clima y los recursos disponibles. En este sentido, el desierto dista mucho de ser un lugar sostenible por su necesidad de infraestructuras y el abastecimiento de elementos fundamentales para la vida humana. El modelo de la minería genera grandes beneficios materiales en el marco de la economía global, pero causa importantes perjuicios en materia medioambiental y dispone una artificialización urbana tan transitoria como condicionante para el propio desarrollo humano. 
La presencia del desierto es constante en la película, características de la representación que no son solamente un recurso expresivo y metafórico en el entorno de la historia. Los protagonistas se ven obligados a adoptar mecanismos de resistencia y adaptación frente a la adversidad frente a un medio natural hostil. Lo extremo del territorio no impide que las relaciones se produzcan con naturalidad, adaptándose sus pobladores al hábitat del desierto.

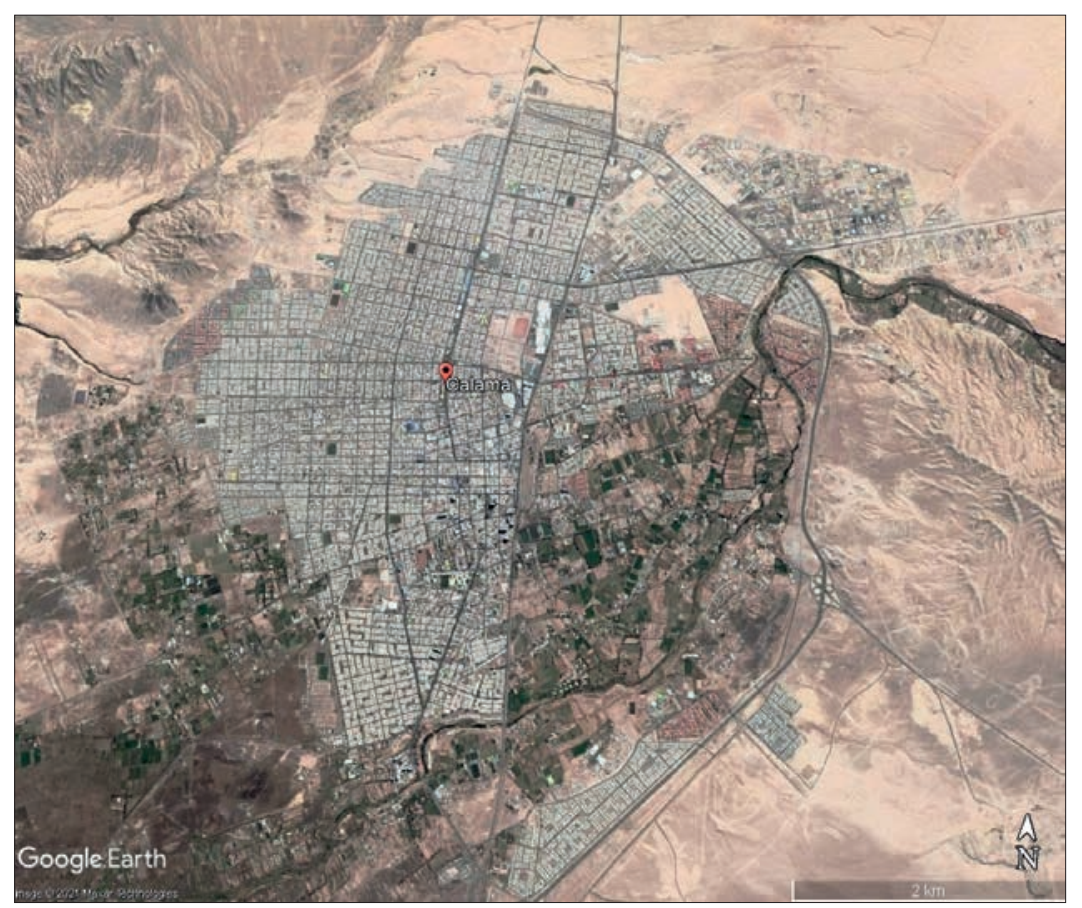

Figura 1. VISTA aÉrea de LA CIUdAd de CALAMA, INSERTA en EL DESIERTO. Fuente: Digital Globe 2021. Google Earth

A través de planos generales, se puede distinguir el espacio urbano de la ciudad nortina, el amanecer y el anochecer en el desierto, observándose incluso las estrellas del firmamento y la contaminación lumínica de las farolas de Calama. La película refleja la notable diferencia entre barrios, fundamentalmente a nivel urbano y arquitectónico, una proyección de dichos niveles que va desde el asfaltado arcén del local de empeños a los polvorientos viales de las calles y viviendas más humildes donde viven los niños, con una techumbre plana que suele ser de zinc o incluso carecer de cubierta, en relación con la escasa pluviosidad de la zona. Ejemplo de ello son los tejados de las viviendas, convertidos en un espacio de almacenamiento más, utilizándose para guardar distintos enseres y objetos. Todo ello contrasta con el verde y regado césped del estadio de fútbol del Cobreloa (Figura 2).

El partido o «pichanga» de los niños visualiza de forma palmaria la precordillera, pues se desarrolla en un solar agreste lleno de guijarros cercano a la zona urbanizada. Un lugar que marca ineludiblemente cómo los habitantes viven en el propio desierto, que es la cancha donde juegan los niños. Los cerros vecinos son testigos de cómo el viento y el sol se desplazan mientras los niños juegan, ejemplo de su capacidad para soportar la dureza climatológica del lugar. 

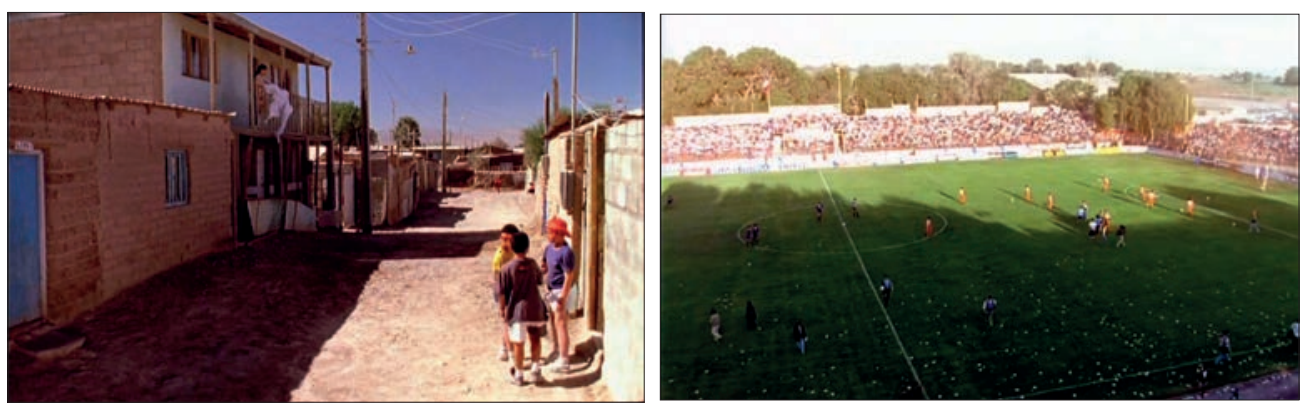

FIGURA 2. CONTRASTE ENTRE LAS VIVIENDAS PERTENECIENTES AL BARRIO DONDE RESIDEN LOS PROTAGONISTAS (IZQUIERDA) Y EL PASTO VERDE DEL CAMPO DE FÚTBOL PROFESIONAL ESTADIO MUNICIPAL ZORROS DEL DESIERTO DE CALAMA (DERECHA) EN «SEGUNDO TIEMPO». Fuente: captura de Historias de fútbol (Andrés Wood, 1997)

\subsection{EL FÚTBOL, DOS CARAS DE LA MONEDA}

El fútbol funciona como catalizador y como juego infantil, pero también como un elemento de cohesión social. Tanto jugadores profesionales como seguidores de cada uno de los equipos y como los niños que conforman su propio equipo poseen un sentimiento de pertenencia a una colectividad. El film representa el fútbol «tout-court»: un juego, pero en el que siempre hay ganadores y perdedores. El deporte profesional que muestra el film no es el de los valores coubertinianos, en el que primaban los principios éticos fundamentales, sino el de los rasgos capitalistas donde lo importante es ganar y hasta los niños y la regla del último gol gana señala indefectiblemente la competitividad entre pares. En este sentido hasta los niños fuera del estadio montan una pequeña pelea sobre quién es el portero más fuerte entre ellos. Se confirma, por tanto, la teoría de Redeker según la cual el deporte también «instila en cada uno el sentimiento de la legitimidad de la ley individualista del más fuerte» (Redeker, 2002, p. I03).

Otro ámbito que asume el fútbol en el largometraje es el de espectáculo. El partido entre los dos equipos profesionales supone un gran evento para la ciudad de Calama y para todo Chile que «asiste» al encuentro gracias a las retransmisiones televisiva y radial. El fútbol, deporte profesional por antonomasia en América Latina, es un espectáculo jugado por profesionales (con sus divisas uniformadas), un negocio para los clubes y la liga patrocinadas por decenas de empresas nacionales e internacionales y vigilado por los antidisturbios para evitar el fenómeno de la violencia entre las diferentes barras de aficionados.

La emoción por el futbol está representada en la escena en la que Pablo, con cuatro de sus amigos, intentan acceder al Estadio municipal de Calama, terreno de juego del Cobreloa. El club de fútbol de la ciudad atacameña se dispone a jugar frente a la Universidad de Chile ${ }^{4}$. Los niños, superan el control policial, pero, al carecer de entrada por no disponer de los medios económicos para comprarlas, no

4. Se trata del partido de ida de la eliminatoria para obtener un cupo y concurrir a la Copa Libertadores de la temporada 1996. 
consiguen acceder a la cancha. Rechazados por la seguridad del estadio -es decir por un sistema capitalista que marginaliza a los pobres- se sitúan en los muros exteriores del recinto para escuchar lo que pasa dentro.

El ambiente festivo, dentro y fuera del estadio, representa también a los calameños que pueden comprar una entrada para ver un partido profesional y a los que, por la escasez de sus medios económicos se lo impiden. La efervescencia se enfatiza con los canticos de los aficionados, de nuevo, dentro y fuera del estadio, o encarnada en la emisión de un locutor que habla de «la emoción del fútbol». Esta escena subraya cómo el deporte, y en concreto el futbol enciende las pasiones de los chilenos en general, y de los calameños en particular, y cómo durante este ambiente festivo las diferencias entre clases sociales se diluyen y ricos y pobres disfrutan, cada uno a su manera, del acontecimiento.

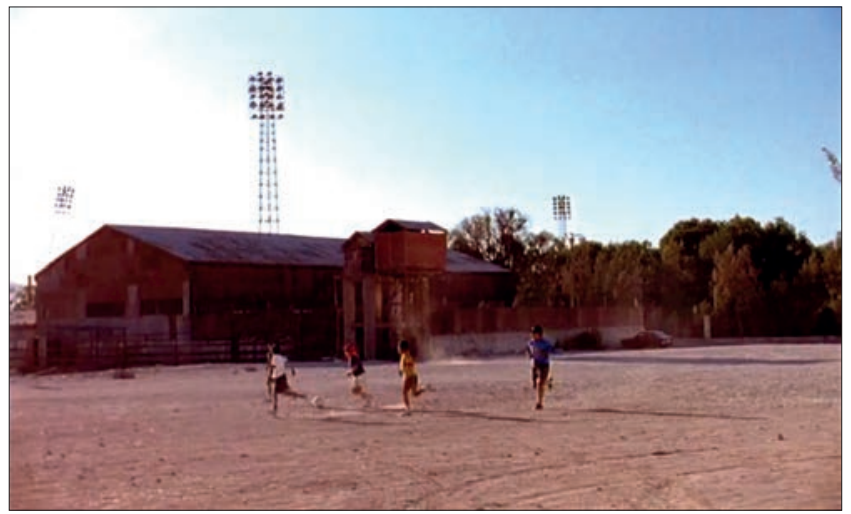

FIGURA 3. PABLO Y SUS AMIGOS ESCAPAN CON EL BALÓN PROFESIONAL EN «SEGUNDO TIEMPO», CONTRASTANDO EN EL PAISAJE UN ANTIGUO EDIFICIO INDUSTRIAL ABANDONADO CON LOS GRANDES FOCOS DEL estadio municipal de CALAma y el arbolado que le circunda. Fuente: Captura de Historias de fútbol (Andrés Wood, 1997)

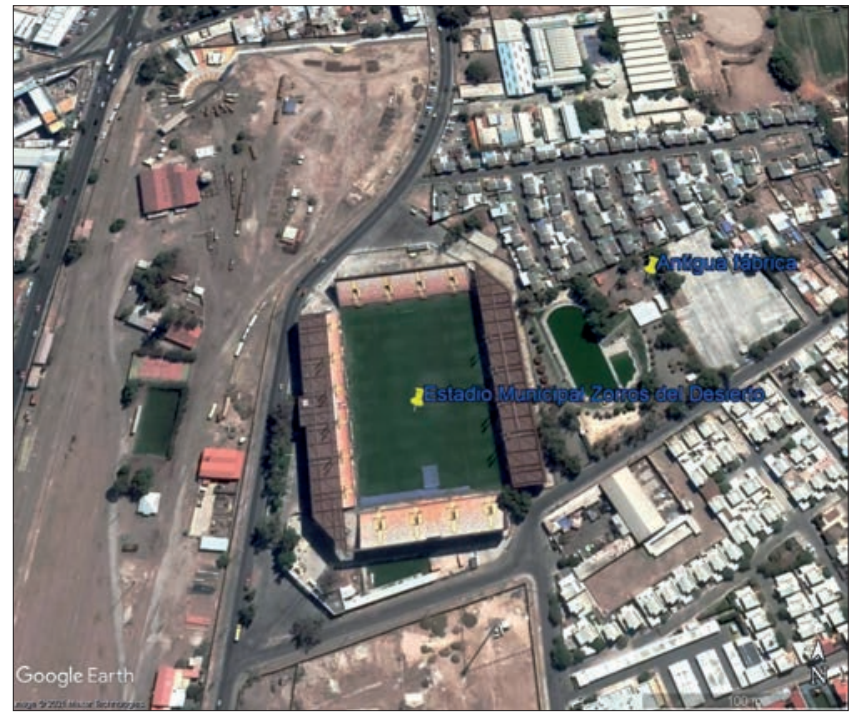

FIGURA 4. LOCALIZACIÓN GEOGRÁFICA DEL ESTADIO MUNICIPAL Y LA ANTIGUA FÁBRICA ANEXA QUE SE OBSERVA EN LA FIGURA 3, SIENDO HOY EL PARQUE ACUÁTICO DE CALAMA, DEPENDIENTE DE LA MUNICIPALIDAD. FUENTE: Digital Globe 2021. Google Earth 
La última intervención del periodista describe la acción de un balón alto que se pierde fuera del estadio y cae a los pies del grupo de niños, que toman el balón y se dirigen a su barrio con el preciado botín, atravesando fábricas ya en desuso (Figura 3 y 4) mientras los jugadores aguardan a que la pelota sea devuelta. El balón de futbol profesional representa, más allá de un coleccionismo deportivo memorabilista, la brecha económica que existe: un objeto que está fuera de su alcance y que de otra manera hubiera sido imposible de conseguir. El balón de los jugadores profesionales no tiene nada que ver con las pelotas artesanales «fabricadas» por los niños calameños. Sin embargo, es un botín compartido, ninguno de los niños se hace con él para su propio beneficio, sino que la propiedad la sortean a través del eructo más largo. La propiedad es del protagonista, pero, sin embargo, esa propiedad individual siempre será compartida, porque el futbol es un juego colectivo, por lo que sus amigos se beneficiarán de ese objeto. Así, todos los amigos deciden jugar un partido entre ellos con dicho balón de futbol simulando, someramente, un partido profesional.

El juego de los niños de Calama ya no es un juego como lo entendían en la antigüedad. Esto se advierte en la organización y la especialización de cómo se disponen, apreciando cómo Pablo les dice a sus compañeros cuál es su posición en la cancha y su rol. Además, se contemplan un mínimo de reglas, desde el ancho de las porterías a las faltas o los fuera de banda, entre otras normas, y existe un objetivo, pues el fin es la victoria. Estos puntos pueden ser comunes con el deporte profesional (Guttmann, I978; Huizinga, 2007). Sin embargo, junto a las mencionadas analogías se perciben diferencias frente al profesionalismo deportivo pues a pesar del afán por ganar, representado en el baile y las risas del grupo de los «perdedores», donde el juego es más un pasatiempo que una competición. En esta línea, los niños no pertenecen a instituciones ni clubes sociales o deportivos, pues los equipos se configuran dependiendo de la amistad entre los integrantes de los mismos; por ende, no existen los patrocinadores en el área de juego ni los anuncios que éstos disponen en los estadios profesionales. Al carecer de equipaciones iguales y patrocinadas, la manera de distinguir a cada equipo es que uno lleva camiseta y el otro equipo va con el torso desnudo bajo el sol del desierto. En el partido que juegan los niños no hay público y la diversión que genera la pugna la disfrutan solo ellos. En el espacio deportivo e no hay regulación pues no tienen arbitro y muchos menos seguridad o policía que obligue a respetar códigos o reglamentaciones y, por supuesto, los medios de comunicación no retransmiten el partido y no darán datos ni estadísticas con las que analizar la disputa deportiva. Los niños expresan una total libertad en el juego, ajenos a convenciones o formalidades.

En Wood, el añadido de la relación entre juego y deporte es fundamental para entender la sociedad calameña de finales del siglo XX. Los cuerpos de los niños están forjados por el clima, la altitud, y una vida muy precaria, donde su único medio de transporte son sus piernas junto a su fuerza física. En contraposición, se hace evidente la exposición de los cuerpos hipertróficos de los futbolistas profesionales de los dos equipos que representan la visión moderna del deporte: donde el cuerpo está sometido al «diktat» del récord, «del rendimiento y de la eficacia cuantitativamente medible» (Redeker, 2002, p. I6) y de un canon de belleza subyugado a la venta de productos. 
Los futbolistas profesionales como «sándwich men» (Redeker, 2002, p. 56) difieren mucho de unos niños que todavía no han tenido que rendirse a todas las leyes de la sociedad capitalista.

\subsection{POBREZA E INFANCIA EN EL DESIERTO}

La escasez y precariedad económica asociada a la infancia es representada en diferentes escenas de la película. La más evidente se muestra en la configuración de la vivienda habitual del protagonista, con enseres populares y donde la única decoración es una reproducción de Il cenacolo o L'ultima cena (La última cena, I495I498) de Leonardo Da Vinci, la cual deberá ser empeñada para mitigar la complicada situación de la familia, intuyendo la posibilidad de que anteriormente otros objetos que decoraban la vivienda hayan sido ya vendidos, remarcando la capacidad para subsistir, alegoría de la escasez y de la miseria que es el penúltimo recurso para seguir sobreviviendo a las penurias. El cuadro es una reproducción pictórica de limitada calidad del fresco milanés del maestro italiano, que es adquirido por el dueño de la casa de empeños motivado por el valor religioso del objeto. La naturaleza religiosa de la imagen como representación de Cristo y sus discípulos es también el motivo por el que hasta ese momento la madre de Pablo será reticente a desprenderse de la misma, deprendiéndose de todo ello la idiosincrasia de la religión católica en la zona.

El dinero que consigue Pablo al empeñar el cuadro mencionado, lo pierde tras finalizar el partido que juega con sus amigos. Apesadumbrado por no poder llevar dicho dinero a casa, decide empeñar el balón de futbol profesional, con un alto valor sentimental para él, pero también un valor monetario importante para las escasas finanzas de su familia. Su amigo Fernando le espera fuera de la tienda del prestamista y juntos vuelven a sus casas con la tristeza del balón empeñado, pero con el dinero en el bolsillo. Esta escena, final de la historia, resume de manera perfecta el dualismo, latente en todo el metraje, entre juego y deporte, pobreza y riqueza, niñez y edad adulta, amistad versus violencia, diversión versus dinero (Figura 5).

La fraternidad entre los amigos se observa a lo largo de la película: comparten el juego, el balón, la situación socioeconómica y hasta la bebida. Después del partido, compran una Coca-Cola, de manera colectiva, para saciar su sed. El refresco de la empresa estadounidense es la representación de un producto globalizado. Los niños deciden comprar esta bebida y no otra que sacie su sed de manera más efectiva. La multinacional se sirve del futbol profesional para promocionar su negocio, siendo desde i950 patrocinador de los Mundiales. Tanto la compra como su uso son compartidos, simbolizando también la escasez económica a la que se enfrentan: adquieren una botella grande para todos al no poder comprarse cada uno de ellos una bebida individual.

La pobreza se observa asimismo en la alimentación del hogar, pues la escena en la que Pablo cena con su madre muestra lo que comen: una salchicha Viena y arroz blanco cocido, sintomático de las apreturas que viven en la casa. El escenario económico de la familia induce a pensar que el cabeza de familia se encuentra desempleado (la imagen paterna no está representada en el film y sólo es mencionada en 
una ocasión). La situación de Pablo es más desesperada por su condición de hijo único y el futuro parece señalar que su incorporación al mercado de trabajo será temprana por las urgencias con las que vive la familia.

En la cancha, Pablo se olvida de su difícil situación. El juego hace que se evada de las pesadumbres de su vida, pero también de la responsabilidad contraída con su madre. La configuración de la familia de Pablo es vista con distanciamiento en el film, subrayando la relación entre madre e hijo, pero evidenciando que el ámbito de la calle y los amigos tienen una presencia mayor que el sustrato familiar del protagonista. Además de lo anterior, Wood acentúa la ausencia del cabeza de familia y la situación laboral de desempleo del mismo, contexto solamente intuido por el espectador y que vendría a contraponerse con la prosperidad minera de la ciudad nortina.

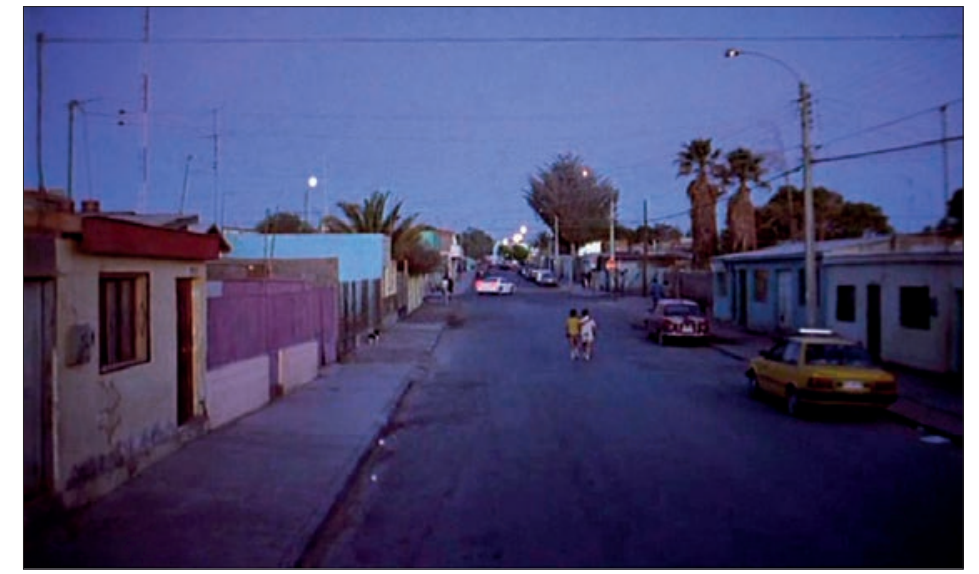

FIGURA 5. PLANO FINAL DE PABLO Y FERNANDO VOLVIENDO A CASA EN «SEGUNDO TIEMPO». Fuente: captura de Historias de fútbol (Andrés Wood, 1997)

La amistad es subrayada con la acción de compartir: se comparte juego, bebida, helados, dinero, alegría, pero también situaciones de tristeza y penuria. El hecho de conseguir de forma espontánea un balón de futbol profesional y la satisfacción de poder jugar con él para después tenerlo que empeñar, muestra la fugaz felicidad de la victoria, en un mundo que obliga a madurar demasiado pronto a los niños. El doloroso desenlace del joven -donde hasta las pasiones tienen precio - le obliga a entrar en la tienda de préstamos. Un niño solo en un mundo de adultos, donde el dinero se convierte en el único juez sobre el futuro de su infancia y la de tantos otros como él.

\subsection{INTERRELACIONES ENTRE LOS ELEMENTOS}

La infancia parece difuminada por las rigurosas condiciones de vida y se desarrolla en una ciudad aislada en el desierto, donde su población aprende a vivir en duros contextos económicos, sociales y ambientales, sin muchas distracciones ni divertimentos. Se reflejan valores como la amistad y la lealtad, aunque sin embargo se obvia la vinculación pampina de la familia. El relato no subraya el enorme 
significado de la tradición familiar y cultural nortina en la memoria y el imaginario de la Pampa chilena (Calderón Gajardo, 20I4).

La difusión del fútbol en la región está relacionada con las explotaciones mineras, proceso análogo a lo sucedido en Europa, en donde gracias al comercio y el negocio mineros (Bilbao, Huelva, Oporto o Génova) o del ferrocarril (Le Havre), el balompié se convirtió en un fenómeno social y cultural. Es decir, fue gracias a la industria y a la economía en general que el fútbol se convirtió en un espectáculo globalizado (Brohm, I982; Robertson y Giulianotti, 2006). Como afirma Brenda Elsey, el fútbol llegó a Chile de la mano del comercio y de la industria europeos, en particular británicos: bancos, minerías y escuelas de idioma -foreign language schools- (Elsey, 20II, p.I9).

En el momento en el que los niños juegan el partido, cae el sol y el partido debe concluir. La contienda deportiva, como juego organizado y competitivo (Gutmmann, I978), se resuelve con el lema «último gol gana», fruto de una visión del fútbol que no es solamente lúdica, sino contaminada por la influencia del deporte profesional que ensalza a los ganadores y el éxito, valores preminentemente capitalistas. Como afirma Eduardo Santa Cruz sobre el desembarco del fútbol en Latinoamérica, especialmente en Chile, Argentina y Brasil, «la aparición del fútbol se inscribe en un proceso global de transformación [...] que es expresión [...] del modo de producción capitalista» (Santa Cruz, I998, p. I58). En este sentido, Pablo propone la regla del «último gol gana» y todos están de acuerdo. No es una casualidad que esa consigna dé título al segundo segmento del largometraje, recordando que hasta los niños juegan con las mismas reglas de los mayores, es decir las de una sociedad impregnada por el valor de la victoria.

El fútbol pasa a ser el instrumento perfecto no sólo para la cohesión social sino también para promover un imaginario de nación, aunque el espectador puede no llegar a percibir que el partido que aparece en el film no es un evento deportivo o futbolístico cualquiera. La importancia de la identificación de Calama con su equipo, el Cobreloa, es un motivo de orgullo y cuando se enfrenta a clubes capitalinos como Colo-Colo o Universidad de Chile, como es el caso de la película, el partido se convierte en la representación de la rivalidad y la lucha de los nortinos en general y de los calameños en particular frente a las escuadras que representan el centralismo chileno. El partido no refleja sólo la rivalidad entre periferia y centro, sino la oposición entre pobreza y riqueza.

En este sentido se pueden identificar tres consideraciones que exponen las dificultades inherentes a un espacio físico de exclusión social y al deporte como elemento que configura las relaciones de los niños:

* El juego y el fútbol son vertebradores del ocio de la infancia. El balón perdido que cae en manos de los niños durante el partido es el objeto motriz del relato fílmico y la competición escatológica que se produce entre ellos funciona como un vehículo para estrechar los lazos de la amistad infantil y para ganarse no sólo la pelota, sino también el liderazgo del grupo.

* A través del balón se produce una lección de vida, alegoría del proceso de madurez que sufre el protagonista. La realidad es asumida por el niño y ante 
la disyuntiva de la necesidad no duda en sacrificar el objeto de deseo y juego que es el balón, priorizando mitigar la carestía que sufre su familia.

Por todo ello, el fútbol en «Último gol gana», como en los otros dos capítulos del largometraje, cumple un desempeño que manifiesta el hecho y el contexto de dicho deporte como metáfora de cohesión social, proceso de transmisión de valores y espejo de la sociedad capitalista y del espectáculo en su vertiente profesional.

\section{DISCUSIÓN Y CONCLUSIONES}

El cine de Wood nutre el imaginario colectivo y la representación de las especificidades y tradiciones chilenas (Peirano, 2005), configurando «una visión de la sociedad [...] honesta [...] A diferencia de la mayoría de las obras de sus coetáneos, las de Wood [...] han sido pensadas desde un afán emotivo de identificación y no desde la mera conmoción espectacular» (Montero Muñoz y Valdebenito Fica, 20I3, pp. I37-138). La manifiesta capacidad del film del director santiaguino para mostrar elementos de la identidad nortina se hace visible a la hora de mostrar el imaginario del Chile contemporáneo, pues tal y como detalla María Paz Peirano (2006) la obra de Wood marca un antes y un después (Peirano, 2006, p. I22).

La relación que se establece entre los imaginarios de un momento determinado condiciona ejemplos de comunicación en el que muchos directores adoptan una posición en sus relatos fílmicos que abunda en lo estereotipado y en lo convencional, reduciendo de forma mínima realidades que, en menor medida, otros realizadores se proponen mostrar de forma más sincera y minuciosa. Por eso Wood repara en la identidad, en esa chilenidad vinculada a la «cultura popular» -y en esa definición cabe recordar la importancia del fútbol, verdadero hilo conductor de la cultura chilena desde hace más de un siglo-, describiendo la identidad del calameño, caracterizando elementos visuales ligados al entorno popular regional chileno, aunque por concisión o elección creativa se obvien realidades nativas, también debido a la exigua relevancia de las mismas en el contexto social mostrado.

El cine de ficción no sólo responde a las demandas y al gusto de los consumidores, sino que se convierte en un valioso instrumento de análisis en términos de representación social y cultural. Esta cultura representada debe ser tomada y considerada con objetividad. Wood ha mostrado con recurrencia en su producción una singular imagen del «otro», con una perspectiva popular, aunque como manifiesta «Último gol gana» y en concreto el segmento analizado, modificando algunas de las perversiones de un cine que, en el ámbito regional, se regodea con frecuencia en lo lumpenesco y en lo populachero, para así atraer a públicos masivos, alejándose de las múltiples realidades latinoamericanas.

De esta manera, el cine se convierte en un instrumento de análisis objetivo, representando realidades sociales y culturales, ocupándose de mostrar las duras condiciones de las clases más desfavorecidas de América Latina. La visión de Wood se identifica con el caso chileno; pero otros creadores contemporáneos (Anexo I) se han ocupado de espacios que muestran muchas analogías, desde Estación central 
de Brasil (Central do Brasil, I998) de Walter Salles en relación con el analfabetismo, La hamaca paraguaya (2006) de Paz Encina indagando en la soledad y pobreza en el contexto de la selva paraguaya o el argentino Pablo Trapero en Elefante Blanco (20I2) abordando el chabolismo porteño.

A la hora de tratar y retratar la pobreza, Wood no aborda su representación apelando a la sordidez o cayendo en una impostada crudeza para exponer la miseria material de la historia. El uso que hace del relato audiovisual, con la obvia mediación del guión, no es el resultado de una narración estereotipada o costumbrista, sino que busca un realismo próximo a la cotidianeidad de los niños calameños que dan voz y cuerpo al film, virtudes más cercanas al género documental. 


\section{BIBLIOGRAFÍA}

Atkinson, J.L., y PLEw, M.S. (20I7). Present, perceived as old, but not memorable: Analysis and perceptions of older characters in animated Disney films. International Journal of Humanities and Social Science, 7, I-I2.

BuCCAFUSCA, L. (2015). The Potential of Youth: An analysis of race and gender representations and their social implications in Young Adult film adaptations. Undergraduate Honors Theses, University of Colorado. https://scholar.colorado.edu/concern/undergraduate_ honors_theses/4mgodwi6n. Recuperado el 30 de noviembre de 2020.

Brohm, J.M. (Ed.) (I982). Sociología Política del Deporte. Fondo de Cultura Económica.

Calderón-Gajardo, R. (20I4). Porque allá nací y allá me crié. Identidad y memoria de los últimos habitantes de la Pampa salitrera de Tarapacá. I930-I979. El caso de los pampinos de Arica. Diálogo Andino, 45, 5I-6I.

Colella, F. (20I7). The Representation of Migrants in Italian Cinema, from the Stereotypes to the Socio-Political Mission of Present-Day Film Directors. Italian Sociological Review, 7 (2), I65-I8I. http://dx.doi.org/I0.13136/isr.v7i2.I72. Recuperado el 3I de octubre de 2020.

Elsey, B. (20II). Citizens and Sportsmen: Fútbol and Politics in the Twentieth-Century Chile. University of Texas Press.

ErighA, M. (20I5). Race, Gender, Hollywood: Representation in Cultural Production and Digital Media's Potential for Change. Sociology Compass, 9, 78-89. https://doi.org/Io.IIII/ SOC4.I2237. Recuperado el 20 de enero de 2020

Gallardo, M. \& García-Reyes, D. (2018). Exploring Chile: Identities and Their Relation with the Environment through the Film Football Stories. Journal of Geography, II7 (3), 205-2I5. https://doi.org/IO.I080/0022I34I.20I8.I430I63. Recuperado el 5 de julio de 2020.

GarcíA-Reyes, D. (20I8). Traslaciones espaciales en «Puntero izquierdo» de Mario Benedetti y «No le crea» de Andrés Wood. Logos: Revista de Lingüística, Filosofía y Literatura, 28 (I), 65-74. https://doi.org/IO.I5443/RL2806. Recuperado el 5 de julio de 2020.

García-Reyes, D. \& Gallardo, M. (2015). La Geografía chilena a través del cine de Andrés Wood. En De la Riva, J; Ibarra, P; Montorio, R. y Rodrigues, M. (eds.). Análisis espacial y representación geográfica: innovación y aplicación. Universidad de Zaragoza, I405-I4I3.

Gauci, V., \& CAllus, A.M. (2015). Enabling everything: scale, disability and the film «The Theory of Everything». Disability \& Society, 30, I282-I286.

Gillespie, A. \& ZitToun, T. (2013). Meaning making in motion: bodies and minds moving through institutional and semiotic structures. Culture \& Psychology, I9, 518-532. https:// doi.org/IO.II77/I354067XI3500325. Recuperado el 25 de octubre de 2020.

Goldgel-CARBAllo, V. (20I4). The reappropriation of poverty and the art of «making do» in contemporary argentine cultural productions. The Global South, 8, 20I, II2-I27.

GutTmann, A. (1978). From ritual to record: The nature of modern sports. Columbia University.

HockenHull, S. (2018). All work, no play...: representation of child labour in films of the First World War. Historical Journal of Film, Radio and Television, 39, I-I7. https://doi.or g/IO.I080/0I439685.20I8.1472834. Recuperado el I6 de septiembre de 2020.

Huizinga, J. (2007). Homo Ludens. Alianza Editorial.

Imbert, G. (2010). Cine e imaginarios sociales. Ediciones Cátedra.

Jarman, R. (20I7). Melodrama at the margins: Poverty, politics and profits in Golden Age Venezuelan cinema. Modern Language Review, II2, 645-665. 
Madzarevic, G., \& Soto-Sanfiel, M.T. (20I8). Positive representation of gay characters in movies for reducing homophobia. Sexuality \& Culture, 22, 909-930. https://doi.org/I0.1007/ SI2II9-0I8-9502-x. Recuperado el 5 de noviembre de 2020.

MAY, J., \& RAMSLAND, J. (2007). The Disenchantment of Childhood: Exploring the Cultural and Spatial Boundaries of Childhood in Three Australian Feature Films, I920s-I970s. Paedagogica Historica, International Journal of the History of Education, 43, I35-I49. https:// doi.org/I0.I080/0030923060I080626. Recuperado el I2 de noviembre de 2020.

Montero-Muñoz, L., y Valdebenito-Fica, F. (2013). La última década del cine chileno: Inevitablemente Independiente. Santiago. Tesis de Grado de la Universidad de Chile. http:// repositorio.uchile.cl/handle/2250/134714 Recuperado el I5 de agosto de 2019.

Nieto-Codina, A. (20II). Las ciudades en el cine de Alfred Hitchcock. Una aproximación a los estudios fílmicos desde el ámbito de la geografía. Espacio, Tiempo y Forma, Serie VI, Geografía, 4-5, I23-I40. https://doi.org/I0.5944/etfvi.4-5.20II.I3726. Recuperado el I8 de noviembre de 2020

Ortega-CAicedo, A. (20IO). Estudio Introductorio. En Pérez Torres, R. Un siglo de ausencia y otros cuentos, (pp. 7-36) Libresa.

Ogando-Díaz, B. (20I6). Geriatría y cine: una mirada desde la salud. Revista de Medicina y Cine, I2, 196-204.

Peirano, M.P. (2005). Imágenes de la nación en el cine chileno actual: la representación de «lo chileno» como cultura popular. Revista Chilena de Antropología Visual, 6, I39-I74.

Peirano, M.P. (2006). Chile en el imaginario cinematográfico del boom (I997-2004). Revista Chilena de Antropología Visual, 8, I2I-I42.

Pérez-Torres, R. (20I0). Cuando me gustaba el fútbol. En Pérez Torres, R. Un siglo de ausencia y otros cuentos. Libresa, 95-99.

Plate, S. B. (Ed). (2003). Representing religion in World Cinema. Filmmaking, Mythmaking, Culture Making. Palgrave Macmillan.

RedeKer, R. (2002). Lo sport contro l'uomo. Troina: Città Aperta Edizioni, 2002.

Robertson, R., \& Giulianotti, R. (2006). Fútbol, Globalización y Glocalización. Revista Internacional de Sociología, 4, 9-35.

Santa-Cruz, E. (1998). ¿Hacia dónde va nuestro fútbol? Nueva Sociedad, I54, I57-I67.

Schurmans F. (2015). The Representation of the Illegal Migrant in Contemporary Cinema: Border Scenarios and Effects. RCCS Annual Review, 7, I32-I50. https://doi.org /I0.4000/ rccsar.622. Recuperado el I8 de junio de 2019.

SHAw, D. (20I4). Sex, text and money, funding and Latin American queer cinema: The cases of Martel's La niña santa and Puenzo's XXY. Transnational Cinemas, 4, I65-184. https:// doi.org/IO.I386/trac.4.2.I65_I. Recuperado el 20 de julio de 2019.

SinYARD, N. (I992). Children in the movies. St. Martin's Press.

Stevens, K. (2013). Dying to love: Gay identity, suicide, and aesthetics in A Single Man. Cinema Journal, 52, 99-I20. https://www.jstor.org/stable/43653150. Recuperado el i9 de noviembre de 2019.

Streib, J., Ayala, M., \& Wixted, C. (20I7). Benign inequality: frames of poverty and social class inequality in children's movies. Journal of Poverty, 2I, I-I9.

VERGARA, F. (20I4). El cine como una herramienta para la comprensión geográfica. Revista Geográfica de Valparaíso, 49, 80-97. 


\section{ANEXO I. FILMOGRAFÍA EN RELACIÓN CON LA TEMÁTICA ANALIZADA}

Alcantud, M. Diamantes negros. Fado Filmes; Potenza Producciones, 2013.

Amado, C. Capitães da Areia. Lagoa Cultural \& Esportiva; MGN Filmes; Maga Filmes, 20 II. Arbeláez, C.C. Los colores de la montaña. El Bus Producciones; Jaguar Films, 2010.

BabenCo, H. Pixote a lei do mais fraco. Embrafilme; HB Filmes, I980.

BUÑUEL, L. Los olvidados. Ultramar Films, I950.

Chaplin, Ch. The Kid. First National Picture, I92I.

Coll, J. La Araucana. Lautaro Films; MGB Cinematográfica; Paraguas Films S.A, I97I.

Donoso, J. Parío y criao. Infractor Producciones; Marandino Films, 2019.

Encina, Paz. La hamaca paraguaya. Black Forest Films; M6 Films; Fortuna Film; Lita Stantic Producciones; Silencio Cine; Wanda Visión; Arte France Cinéma, 2006.

FAvı, L. Crónica de un niño solo. Real Films, I965.

Fernández Almendras, F. Mi amigo Alexis. Fabula, 2019.

Francia, A. Valparaíso mi amor. Cine Nuevo, I969.

Gaviria, V. La vendedora de rosas. Producciones Firmamento, I998.

Guzmán, P. Nostalgia de la luz. Atacama Productions; Blinker Filmproduktion; Westdeutscher Rundfunk; Cronomedia, 20 oro.

Hamburger, C. O ano em que meus pais saíram de férias. Gullane; Caos Produções Cinematográficas; Miravista, Globo Fimes,20o6.

Heard, M. Tierra Yerma. Forastero; Echo Art Films, 2016.

Hens, A. La partida. Malas Compañías P.C.; Doce Gatos S.L.; El Azar S.L, 2013.

Kiarostami, A. Mossafer.Kanoon, i974.

Larraín, E. Alicia en el país. Piranha Films, 2008.

Larraín, R. El Entusiasmo. CNC; Cine XXI; CARTEL; Fondart; Fonds Sud Cinéma; Paraïso Productions; Tras.Film; ZDF/Arte,I998.

LOACH, K. My name is Joe (I998), ARD Degeto Film; ARTE; Alta Films; Channel Four Films; Diaphana Films; Filmstiftung Nordrhein-Westfalen; La Sept Cinéma; Parallax Pictures; Road Movies Vierte Produktionen; Scottish Arts Council Lottery Fund; The Glasgow Film Fund; Tornasol Films; Westdeutscher Rundfunk (WDR), 1998.

LOACH, K. Looking for Eric. BIM; Canto Bros; Les Films du Fleuve; Sixteen Films; Why Not Productions; Tornasol Films, 2009.

Lund, K. y Meirelles, F. Cidade de Deus. O2 Filmes; VideoFilmes; Globo Filmes; Wild Bunch, 2002.

Moreno, A. Medea. Azabache, 2oIg.

Murúa, L. La Raulito. Helicon Producciones,I975.

MurúA, L. La Raulito en libertad. Eguiluz Films; Lotus Films, I977.

RASQUin, M. Hermanos. A\&B Producciones, 2010.

Rosenfeld, I. Aspirantes. Bubbles Project; Crisis Produtivas, 2015).

Rougier, D. Sal. Cruz Del Sur; Picardia Films, 20II.

Salles, W. Central do Brasil. MACT Productions; VideoFilmes; Arthur Cohn Productions, I998.

Schroeder, B. La virgen de los sicarios. Canal +; Les Films du Losange; Proyecto Tucan; Tornasol Films; Vértigo Films, 2000.

SIERRA, E. La Raulito, golpes bajos. Leonardo Hussen, 2009.

Sото, H. Caliche Sangriento. Icla Films, I969. 
Tolnt, H. Mirage d'amour avec fanfare. Saga Film; P.S. Productions; Centre du Cinéma et de l'Audiovisuel de la Fédération Wallonie-Bruxelles, 2016.

Torres Ríos, L. Pelota de trapo. Sociedad Independiente Filmadora Argentina (SIFA), I948.

Trapero, P. Elefante Blanco. Morena Films; Matanza Films; Patagonik; INCAA; ICAA; Wild Bunch; TVE; Maneki Films; Canal+ España, 2012.

VıGo, J. Zéro de conduite: Jeunes diables au collège. Comptoir Français de Distribution de Films Franfilmdis); Argui-Film, I933.

Wood, A. Historias de futbol. Paraïso Productions; Roos Films,I997. 



\section{4

\section{Presentación · Foreword}

\section{Artículos · Articles}

19 Eugenio Climent López y Samuel Esteban Rodríguez

La crisis económica de 2008 en las Denominaciones de Origen Protegidas de vino españolas: efectos y modelos de salida. The 2008 Economic Crisis in the Spanish Protected Designations of Origin of Wine: Effects and Exit Models

4.5 David García-Reyes, EnRICo Marini y Marta Gallardo

Infancia, pobreza y deporte en el desierto de Calama, Chile. Representaciones sociales en «Segundo tiempo, último gol gana» . Childhood, Poverty and Sport in the Desert of Calama, Chile. Social Representations in «Segundo tiempo, último gol gana»

José Antonio González díaz, Benjamín González díaz y Rocío Rosa GARCía

Revisión de los objetivos de los espacios protegidos: el parque natural y reserva de la biosfera de Redes - Review of the Objectives of Protected Spaces: Natural Park and Biosphere Reserve of Redes

Álvaro-Francisco Morote Seguido

Investigación y enseñanza en didáctica de la climatología. Estado de la cuestión (1980-2020) (España) · Research and Teaching in Didactic of Climatology. State of the Art (1980-2020) (Spain)

\section{Gemma Ruiz Ángel y Mariano Cecilia Espinosa}

Rogativas pro - pluvia en la catedral de Orihuela: La sequía en Orihuela durante el siglo XVII · Rogative Pro - Pluvia in the Cathedral of Orihuela: The Drought in Orihuela during the $17^{\text {th }}$ Century

\section{5}

José Ramón Sánchez Holgado

La puesta en valor de los campos de concentración y exterminio nazis como lugar de memoria . Putting Value of the Nazis Extermination and Concentration Camps as a Place of Memory

\section{7}

LAURA Sevilla CuAdrado

La conciencia medio ambiental en el sector del turismo de sol y playa. Un estudio con la técnica Delphi . Environmental Awareness in the Sun, Sea and Sand Tourism Sector. A Study using the Delphi Technique

The Technopolitics of Mapping Dar es Salaam: An Examination of the Technological and Political Motivations of the Humanitarian OpenStreetMap Team La tecnopolítica de la cartografía de Dar es Salaam: Un examen de las motivaciones tecnológicas y políticas del equipo humanitario OpenStreetMap

\section{Reseñas · Book Review}

19 De LÁzaro Torres, María Luisa y Morales Yago, Francisco José (2021). Introducción a la Investigación en Geografía. Pautas para la Elaboración de Trabajos Científicos (An Introduction to Research in Geography. Guidelines for the Preparation of Scientific Papers). UNED, 223 Pp., ISBN: 978-84-362-7689-3. (JuLIO FERNÁNDEZ PORTELA

Fernández Portela, Julio y Hernández García, Ricardo (2021). Sociedad y territorio en Cubillas de Santa Marta: del Catastro de Ensenada a la actualidad. Ayuntamiento de Cubillas de Santa Marta, 259 pp., ISBN: 978-84-09-28428-3. (MIGUEL ÁngEL GarCía VELASCO)

MÉndez GutiérRez del VALLe, R. (2020). Sitiados por la pandemia. Del colapso a la reconstrucción: apuntes geográficos. Revives, 183 pp. (ROSA MECHA

23 MARTín-Roda, Eva María (2021). Geopolítica de los recursos energéticos. Síntesis, 276 pp., ISBN: 9788413571348 ; ISBN Digital: 9788413576626 (AURELIO NiETO CODINA)

235 Moreno BorrelL, S. (2019). La Naturaleza y el Paisaje de Málaga a través de viajeros, naturalistas y científicos. La Serranía, 224 Pp., ISBN: 978-8415588-28-3 (SERGIO REYES CORREDERA)

\section{Imágenes y palabras · Pictures and Words}

\subsection{JULıo López-DavaliLlo LARREA \\ La laguna de Herramélluri. Un humedal renacido . The Herramélluri Lagoon.}

\section{Síntesis de Tesis Doctorales · Summaries of Doctoral Thesis}

\section{Javier Álvarez Otero}

El uso educativo de las Infraestructuras de Datos Espaciales (IDE) para mejorar la responsabilidad social de los ciudadanos del siglo XXI sobre el territorio. Departamento de Didáctica de las Ciencias Experimentales, Sociales y Matemáticas. Universidad Complutense de Madrid. Directora: Dra. Doña María Luisa de Lázaro Torres. Fecha: 10 de diciembre de 2020

\section{José Fernández Álvarez}

Dinámica evolutiva de los usos y coberturas del suelo en la provincia de Salamanca. Análisis comparado y repercusiones en el paisaje rural de cuatro comarcas de estudio. Departamento de Geografía, Universidad Nacional de Educación a Distancia (UNED). Director: Dr. D. Carlos Javier Pardo Abad. Fecha: 27 de mayo de 2021 